\title{
Uptake of tamoxifen in consecutive premenopausal women under surveillance in a high-risk breast cancer clinic
}

\author{
L S Donnelly ${ }^{*, 1}$, D G Evans ${ }^{1,2}$, J Wiseman ${ }^{1}$, J Fox ${ }^{1}$, R Greenhalgh ${ }^{1}$, J Affen ${ }^{1}$, I Juraskova ${ }^{3}$, P Stavrinos ${ }^{4}$,
} S Dawe ${ }^{1}, \mathrm{~J} \mathrm{Cuzick}^{5}$ and A Howell ${ }^{1,6}$

\begin{abstract}
${ }^{1}$ Nightingale and Genesis Breast Cancer Prevention Centre, University Hospital of South Manchester, Manchester M23 9LT, UK; ${ }^{2}$ Department of Genomic Medicine, MAHSC, St Mary's Hospital, Manchester M13 9WL, UK; ${ }^{3}$ Centre for Medical Psychology and Evidence-based Decision-Making (CeMPED), School of Psychology, University of Sydney, Sydney, NSW 2006, Australia; ${ }^{4}$ Manchester Academic Health Science Centre, University Hospital of South Manchester, University of Manchester, Manchester M23 9LT, UK; ${ }^{5}$ Centre for Cancer Prevention, Wolfson Institute of Preventive Medicine, Queen Mary University of London, London EC1M 6BQ, UK and ${ }^{6}$ Department of Medical Oncology, Christie Hospital, Manchester M20 4BX, UK
\end{abstract}

Background: Randomised trials of tamoxifen versus placebo indicate that tamoxifen reduces breast cancer risk by approximately $33 \%$, yet uptake is low. Approximately $10 \%$ of women in our clinic entered the IBIS-I prevention trial. We assess the uptake of tamoxifen in a consecutive series of premenopausal women not in a trial and explore the reasons for uptake through interviews.

Methods: All eligible women between 33 and 46 years at $\geqslant 17 \%$ lifetime risk of breast cancer and undergoing annual mammography in our service were invited to take a 5-year course of tamoxifen. Reasons for accepting $(n=15)$ or declining $(n=15)$ were explored using semi-structured interviews.

Results: Of 1279 eligible women, 136 (10.6\%) decided to take tamoxifen. Women $>40$ years (74 out of $553(13.4 \%)$ ) and those at higher non-BRCA-associated risk were more likely to accept tamoxifen (129 out of 1109 (11.6\%)). Interviews highlighted four themes surrounding decision making: perceived impact of side effects, the impact of others' experience on beliefs about tamoxifen, tamoxifen as a 'cancer drug', and daily reminder of cancer risk.

Conclusions: Tamoxifen uptake was similar to previously ascertained uptake in a randomised controlled trial (IBIS-I). Concerns were similar in women who did or did not accept tamoxifen. Decision making appeared to be embedded in the experience of significant others.

A recent meta-analysis of four randomised controlled trials of tamoxifen indicates a $33 \%(P<0.0001)$ reduction in all breast cancers compared with placebo (Cuzick et al, 2013). This reduction was mainly due to a larger effect on ER-positive breast cancer where there was reduction of $44 \%$ in invasive breast cancers $(P<0.0001)$ and a significant reduction in DCIS $(P=0.009)$. Although tamoxifen is given for 5 years, follow-up data indicate that the breast cancer occurrence curves continue to diverge for at least 10 years (Cuzick et al, 2007; Powles et al, 2007; Veronesi et al, 2007).
The early positive results of the first randomised tamoxifen prevention trial, which reported a 50\% risk reduction (Fisher et $a l, 1998)$, led to the registration of tamoxifen for use as a preventive agent by the US Food and Drug Administration in October 1998 (US Food and Drug Administration, 1998) and the results of all four tamoxifen trials led to acceptance by the UK National Institute of Health and Care Excellence (NICE) in July 2013 (National Institute for Health and Care Excellence (NICE), 2013). 
Gail et al (1999) estimated the risk/benefit ratio of taking tamoxifen for prevention in relation to age and race. The risk/ benefit ratio was in favour of tamoxifen in virtually all women below the age of 50 years irrespective of degree of elevated risk above the Gail threshold of $1.65 \%$ 5-year risk or of race. Despite early tamoxifen acceptance by the FDA, the data from the Gail analyses, positive recommendations from the American Society for Clinical Oncology and the National Comprehensive Cancer Network (National Comprehensive Cancer Network, 2009; Visvanathan et al, 2013), the use of tamoxifen for prevention of breast cancer is low (Ropka et al, 2010).

Previously, we assessed the uptake of tamoxifen in a high-risk clinic in the context of the IBIS-I tamoxifen prevention trial, which compared tamoxifen with placebo (Cuzick et al, 2007). Entry into IBIS-I occurred between 1993 and 2000. In face-to-face consultations, 2278 women were offered participation in the IBIS-I trial and $12.0 \%$ agreed (Evans et al, 2001, 2010). Potential reasons for this relatively low uptake to IBIS-I may have been women's concerns regarding the randomisation process and the potential for being on a placebo for 5 years (Juraskova et al, 2007). To overcome these issues, the aim of the current study was to assess the uptake of tamoxifen outside of a clinical trial and the impact of breast cancer risk on uptake in a consecutive group of younger women between the ages of 33 and 46 years undergoing annual mammography in our family history clinic (FHC). We undertook semi-structured interviews to explore reasons for uptake or non-uptake of tamoxifen.

\section{MATERIALS AND METHODS}

Recruitment. Information about the study and an expression of interest form with a stamped addressed envelope was sent to all eligible women undergoing annual mammographic surveillance in the Genesis Breast Cancer Prevention Centre FHC. Women requesting more information about the study were given a detailed decision pack when they attended their next routine mammogram. The decision pack contained participant information sheets and a 40-page detailed decision aid (described elsewhere). Women were asked to read the information in the pack, and if interested, were asked to contact the research team upon receipt of a normal mammogram result (approximately 2 weeks after their mammogram). The study was approved by Greater Manchester West Research Ethics Committee (ref: 11/H1014/4).

Eligibility criteria. All women were at moderate or high risk of breast cancer $(\geqslant 17 \%$ lifetime risk by the Tyrer-Cuzick model. Tyrer et al, 2004) and being monitored according to NICE FHC Guidelines (McIntosh et al, 2004, 2006): having annual mammography, annual MRI (if BRCA1/2 carriers), and clinical breast examination (RG and JA). Eligible women were aged 33-46 years, premenopausal (so that uptake was not confounded by concerns of increased risk of endometrial cancer found with tamoxifen use in postmenopausal women; Cheng et al, 1997) had a negative pregnancy test and were willing to use non-hormonal forms of contraception.

Women were excluded if they had a cancer diagnosis in the past 5 years (except basal cell carcinoma or in-situ carcinoma of the cervix), a recent abnormal mammogram, previously taken tamoxifen, raloxifene, or other selective oestrogen receptor modulators for more than 3 months before participation in study, had or planned to have a prophylactic mastectomy, were pregnant or breastfeeding, wished to continue hormonal contraception, had hypersensitivity to tamoxifen or any of its ingredients, had existing uterine complications, personal or family history of thromboembolism, used coumarin-type anticoagulants, droperidol, or buprion. Women were also excluded if they had diabetes, other intercurrent disease, or psychological disturbance, which would preclude informed consent to participate or compliance with the treatment regimen.
Qualitative interviews. A convenience sample of women who decided to take tamoxifen and women indicating that they did not wish to take tamoxifen were invited to take part in an interview study to explore their reasons for and barriers to tamoxifen uptake. Semi-structured interviews were conducted until data saturation had been achieved. Interviews were carried out with 15 women who did and 15 who did not enter the study (Table 1). To be eligible for interview, women needed to fit the above-mentioned eligibility criteria and speak fluent English. Interviews lasted between 45 and $90 \mathrm{~min}$, were conducted at either the Genesis Breast Cancer Prevention Centre or in the participants' own home. Interviews were audio-recorded, transcribed verbatim, and analysed using framework analysis following five methodological steps: familiarisation with the data, identification of a thematic framework, indexing, charting, and mapping and interpretation of themes (Ritchie and Lewis, 2003).

\section{RESULTS}

Uptake of tamoxifen. The aim of this study was to assess the uptake of tamoxifen and factors influencing this in consecutive women at a breast cancer FHC and describe the characteristics of those women. All 1545 women under follow-up in the FHC who were considered eligible for preventative tamoxifen were contacted. On further enquiry, 266 of these did not meet the eligibility criteria outlined above, leaving 1279 women suitable for preventive therapy with tamoxifen (Figure 1. Consort diagram). Of these, 776 women did not respond to the initial invitation letter. Of the 503 who responded to the invitation, on further contact, $124 \mathrm{did}$ not wish to pursue prevention.

Of the eligible women, 136 decided to take tamoxifen $(10.6 \%$ Figure 1). Median age was significantly higher among women who joined the study (42.3 years) compared with decliners (41.1 years; $\left.\chi^{2}, P=0.026\right)$. Uptake is shown by subdivisions of age and risk in Table 2, indicating a trend towards greater uptake associated with increasing age and increasing risk in the non-BRCA1/2-associated risk group. Women with $B R C A 1 / 2$-associated risk were significantly less likely to take tamoxifen (7 out of $170(4.1 \%)$ ) compared with those not known to have BRCA1/2-associated risk (129 out of $\left.1109(11.6 \%), \chi^{2}, P=0.005\right)$. Uptake was similar across usual risk groups (129 out of $1109(11.6 \%))$ but significantly lower among women tested or not tested for a high-risk gene mutation (7 out of $\left.170(4.1 \%), \chi^{2}, P=0.0019\right)$. The highest uptake was in $41-$ to

Table 1. Demographics of women participating in the interview study

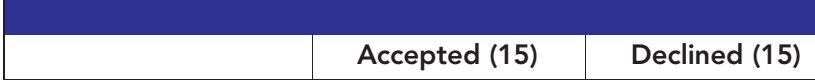

\begin{tabular}{|l|r|r|}
\hline \multicolumn{3}{|l|}{ Age (years) } \\
\hline $33-39$ & 4 & 4 \\
$40-46$ & 11 & 11 \\
\hline
\end{tabular}

\begin{tabular}{|c|c|c|}
\hline \multicolumn{3}{|l|}{ Lifetime risk } \\
\hline $\begin{array}{l}17-25 \% \\
26-39 \% \\
40-50 \% \text { (not BRCA) } \\
51-85 \%\end{array}$ & $\begin{array}{l}6 \\
3 \\
6 \\
0\end{array}$ & $\begin{array}{l}3 \\
7 \\
5 \\
0\end{array}$ \\
\hline \multicolumn{3}{|l|}{ Parity } \\
\hline $\begin{array}{l}\text { Parous } \\
\text { Nulliparous }\end{array}$ & $\begin{array}{r}12 \\
3\end{array}$ & $\begin{array}{c}12 \\
3 \text { (1 adopted) }\end{array}$ \\
\hline
\end{tabular}

Abbreviation: $\mathrm{BRCA}=$ breast cancer 1 or 2, early onset gene mutation 
46-year-old women at $40-45 \%$ lifetime risk of breast cancer (18 out of $104(17.3 \%))$. In contrast to the increasing uptake with risk in those women not known to be at risk of BRCA1/2, women who had tested negative for a mutation in their family were more likely to take tamoxifen $(5 / 55,9 \%)$ than those still at risk of carrying a mutation but not tested ( 1 out of $114(0.9 \%), \chi^{2}, P=0.014$ ).

Interview study. Thirty women (fifteen declined and fifteen took tamoxifen) agreed to undertake a semi-structured interview with LD. The following four themes that appeared seminal to individual decisions to take tamoxifen or not, emerged from the qualitative analysis: the perceived impact of side effects, the impact of others' experience on beliefs about tamoxifen, tamoxifen as a cancer drug, and daily medication as reminder of cancer risk (Table 3 ). Where verbatim quotes are provided 'A' denotes acceptance of tamoxifen, with ' $\mathrm{D}$ ' denoting a woman who declined tamoxifen.

Theme 1: Perceived impact of side effects. Side effects were cited by all of the women as the main consideration when deciding whether to take tamoxifen or not. Both acceptors and decliners were concerned about a range of side effects (Table 3). A5 told us how her decision to take tamoxifen needed to be made jointly with

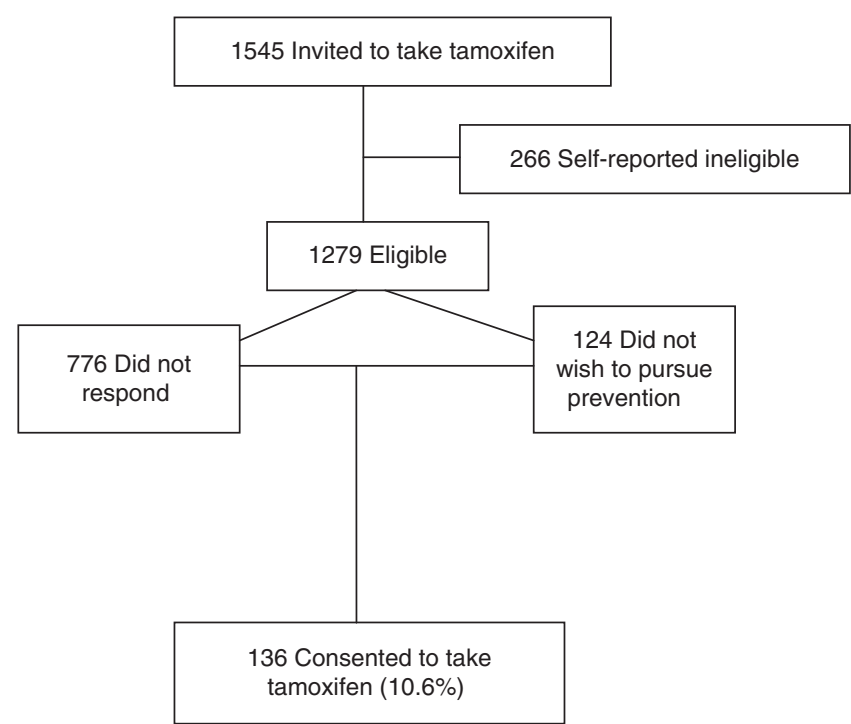

Figure 1. Consort diagram showing total population approached and uptake of tamoxifen. her partner as the medication has potential to impact on the intimacy in their relationship.

A5: [I'm] worried about losing interest in sex, to be honest with you, because that's an important part of our relationship. But because we're aware of it, we'll talk about it. It could cause tensions because if one of you loses interest you could think 'why?' you know 'are you seeing somebody else?' 'What's going on?' It can have quite a catastrophic effect.

Twenty-five of the women interviewed $(A=12, D=13)$ were mothers who felt that an impact on their quality of life would have consequences for their families, particularly young children. D14 was concerned about how side effects may decrease the energy she has to care for her children.

D14: That would be my main reason. Because I think if you're ill, it's beyond control anyway. If you're doing something like a trial for something and it sort of takes away your energy or makes you ill, you've done it yourself and when you've got a young family and you work full time and stuff, I don't think it's what I would like to do.

Although side effects were of concern to all participants, women who joined the study spoke in detail of how they balanced their concerns against the benefits of taking tamoxifen. Nine of the fifteen women who took tamoxifen accepted that they will naturally experience many of the common side effects associated with tamoxifen in the future as part of the menopause.

A3: I am 44 at the minute, 45 in August. So I'm getting to that stage of my life where it's [menopause] coming anyway... like I said you can get hot sweats and cold sweats without being on medication so if you do, at least you've got that little bit of extra peace of mind that you're doing something to prevent something nasty from happening.

In addition, seven of the fifteen women who accepted the offer of tamoxifen balanced their concerns about side effects against the potential to prevent breast cancer, something they placed above their immediate quality of life.

A7: My main motivation, well what do I want to do? Take these pills now or do I want to have... you know. The thought of taking these pills now is not a hardship, but the thought of having chemotherapy in 10 years... to me it's a no-brainer.

Theme 2: The impact of others' experience on beliefs about tamoxifen. Deciding whether or not to take tamoxifen was heavily influenced by the women's social groups. All women sought the opinion of others, particularly those who had experience of taking tamoxifen, with six of the decliners stating that other's opinion of tamoxifen strongly influenced their decision to decline. The anticipated severity and impact of side effects were stronger in those who declined and was often based on a close female relative's

Table 2. Uptake by subdivisions of age and risk

\begin{tabular}{|c|c|c|c|c|c|c|c|}
\hline $\begin{array}{l}\text { Age } \\
\text { (years) }\end{array}$ & $\begin{array}{c}\text { Lifetime risk } \\
17-25 \%\end{array}$ & $\begin{array}{l}\text { Lifetime risk } \\
26-39 \%\end{array}$ & $\begin{array}{l}\text { Lifetime risk } \\
40-50 \% \text { not } \\
\text { BRCA }\end{array}$ & $\begin{array}{c}\text { BRCA } \\
\text { negative }^{a}\end{array}$ & $\begin{array}{c}\text { BRCA } \\
\text { untested }^{a}\end{array}$ & $\begin{array}{c}\text { Lifetime risk } \\
51-85 \% \text { (BRCA1/2 } \\
\text { or TP53) }\end{array}$ & Total \\
\hline $33-35$ & $2 / 40$ & $8 / 63$ & $0 / 26$ & $0 / 4$ & $0 / 17$ & $0 / 11$ & 11/161 (6.8\%) \\
\hline $36-38$ & $9 / 78$ & $8 / 103$ & $6 / 39$ & $0 / 4$ & $0 / 13$ & $1 / 13$ & $24 / 250$ (9.6\%) \\
\hline $39-40$ & $6 / 52$ & $10 / 95$ & $4 / 31$ & $0 / 9$ & $0 / 9$ & $0 / 5$ & $20 / 201(10 \%)$ \\
\hline $41-43$ & $4 / 87$ & $22 / 139$ & $10 / 58$ & $2 / 16$ & $1 / 14$ & $0 / 16$ & $41 / 330(12.4 \%)$ \\
\hline$>43$ & $11 / 101$ & $21 / 151$ & $8 / 46$ & $3 / 22$ & $0 / 9$ & $0 / 8$ & $42 / 337(12.5 \%)$ \\
\hline Total & $32 / 358(9.2 \%)$ & $69 / 551(12.5 \%)$ & $28 / 200$ (14\%) & $5 / 55(9 \%)$ & $1 / 62(1.7 \%)$ & $1^{b} / 53(1.9 \%)$ & $136 / 1279(10.6 \%)$ \\
\hline
\end{tabular}

${ }^{a}$ BRCA (Breast Cancer 1 or 2, early onset gene mutation) negative refers to women who have known BRCA mutations in their family, but have personally tested negative for their familial mutation. BRCA untested represents women who have known BRCA mutations within the family but have not been tested themselves, thus are at a potential $51-85 \%$ risk.

b 1 53 mutation carrier. 


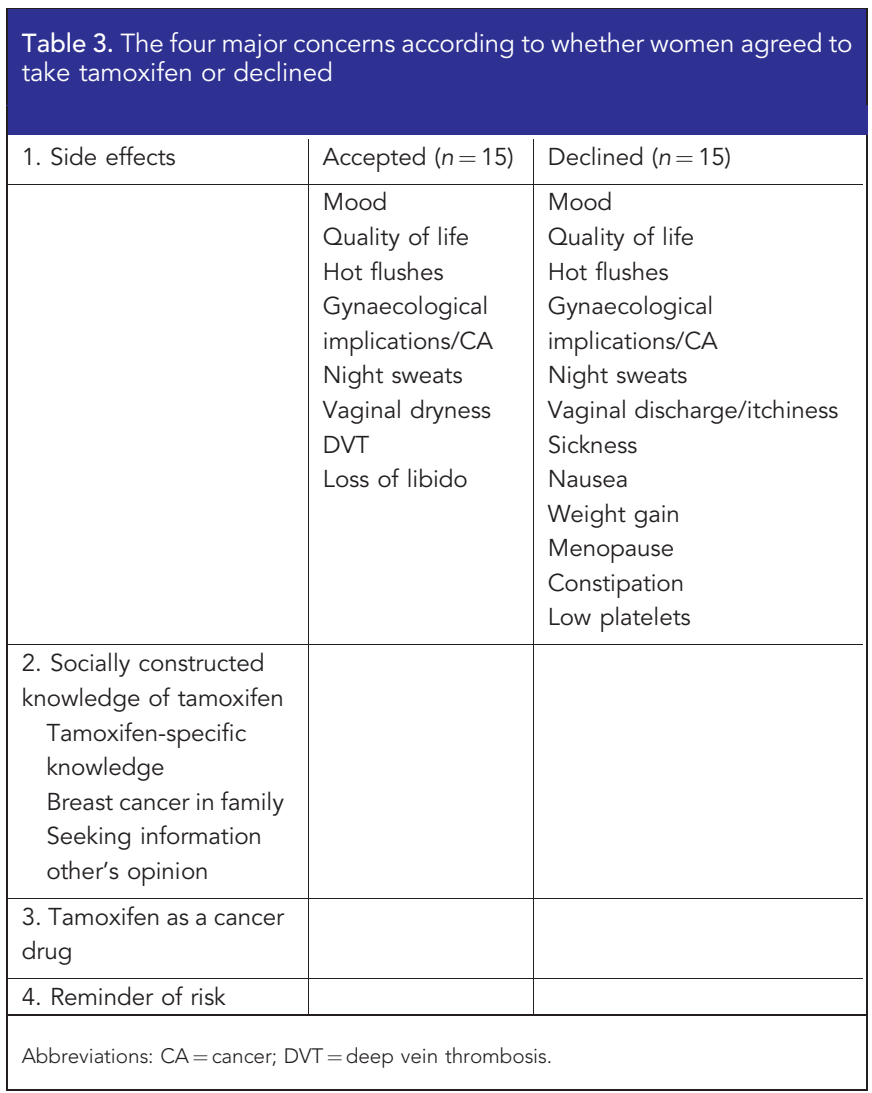

experience of preventive treatment following breast cancer. If the experience was negative, this was reflected in the reasons given for declining tamoxifen, as D15 explains:

D15: My mum actually she was on anastrozole for her prevention and in that space of time she's had, she's developed osteoporosis which they feel may have been linked to anastrozole. So I suppose in a way that affected my view of it, the anti-oestrogen and everything because she had two broken wrists that um needed pinning.

This understanding of tamoxifen also influenced women's perceptions of the effectiveness of tamoxifen for preventing breast cancer. Women whose close friends or family members had breast cancer recurrence despite taking tamoxifen held reservations about the efficacy of tamoxifen in preventing breast cancer, and cited this in their reasons for declinature. When tamoxifen did prevent recurrence of breast cancer, women were more positive about its use in chemoprevention, impacting on their willingness to take tamoxifen.

A10: I think if she was on the tamoxifen and died while she was on the tamoxifen and it wouldn't have been the tamoxifen that killed... You know, I probably would have thought again, I would have thought about it a bit more, you know my mum's had it and she's still here.

Theme 3: Tamoxifen as a cancer drug. For many women, tamoxifen was inextricably associated with cancer and deciding whether to engage in chemoprevention evoked painful memories. For decliners, such as D6, the association of tamoxifen with breast cancer was fundamental in deciding not to take tamoxifen for chemoprevention.

D6: I always relate tamoxifen with cancer because obviously I've got it in the family. I think I tend to relate it with cancer and I don't know whether that's a barrier in my mind that might you know sort of like put me off again.

All of our participants were acutely aware that their family members would also hold strong associations with tamoxifen use. Seven of the acceptors expressed concern about others' reaction to finding out about their decision to electively take tamoxifen. Some women were worried about having to explain to children about their family history of breast cancer, while others, such as A6, were concerned that family and friends may assume she had been diagnosed with cancer and not told them; highlighting a need to support for women choosing to engage with preventive therapy.

A6: Because well a lot of people have heard of tamoxifen and I don't want them coming and seeing I've got tamoxifen and jumping to any conclusions. It's just that people might think that I have cancer or have had cancer and not told them.

Akin to the view that tamoxifen is loaded because of its association as a cancer treatment, both groups felt that tamoxifen might be perceived as having similar effects as chemotherapy. A16 spoke of the importance of explaining to women that tamoxifen has a different side effect profile to chemotherapy, in increasing uptake of chemopreventive strategies.

A16: It's seen as a form of chemotherapy. I think as well the fact that ladies are taking it who've had breast cancer, perhaps some reassurance because people think their hair's gonna fall out. Perhaps it would be helpful to be able to explain the difference between what's traditional like intravenous chemotherapy that does have a side-effect of hair loss and vomiting and things like that as opposed to the tamoxifen which has quite different side effects.

Theme 4: Daily medication as a reminder of cancer risk. The women who declined the offer to take tamoxifen spoke in depth of how taking a drug to prevent cancer would remind them of their breast cancer risk. Being reminded of one's risk was not a prevalent issue to our acceptors.

For eight of the declining women, taking tamoxifen for prevention represented an ultimate acknowledgement of their breast cancer risk. These women were concerned about increasing cancer anxiety and felt that the chances of experiencing side effects would make them acknowledge their risk at times when they would not otherwise have done so.

D2: I suppose it's not taking the pill that reminds you every day; the side effects remind you every day don't they? If you could be guaranteed more or less not to have any side effects the pill would just become routine and maybe you would switch off because you are not having the physical things to constantly tell you 'this pill's doing this to me'.

For other women, breast cancer was not the only health concern in their families. For these women it may be difficult to decide to focus on prevention of breast cancer instead of other salient diseases, as D3 explained here in the context of ovarian cancer.

D3: They're saying my chances of breast cancer are high but there's not really much talk of ovarian cancer and I mean I know that's obviously a lot rarer. I think because I've seen my mum go through that (ovarian cancer).

\section{DISCUSSION}

The aim of this study was to determine the uptake of tamoxifen outside of the context of a clinical trial and in view of the knowledge that, at the time of study conception, tamoxifen could not be prescribed for prevention of primary breast cancer in the UK National Health Service. We also planned to determine the major reasons for uptake and non-uptake using qualitative interviews.

This uptake study was designed to include all women under follow-up review by clinical breast examination and mammography in a breast cancer FHC. This was done in order to minimise potential selection bias and provide estimates for the expected uptake in other FHCs and general practice in the United Kingdom when tamoxifen became prescribable. These women are also representative of the age group referred to FHCs in the United Kingdom. 
The uptake in the 1279 eligible women was 10.6\%, a figure slightly lower than the $12.0 \%$ uptake reported for the IBIS-I tamoxifen prevention trial (Evans et al, 2010; Table 4). The figure of $10.6 \%$ represents an average uptake. Higher uptake was seen in women at high risk (40-45\% lifetime risk) between the ages of 41 and 46 years (17.3\%). The lowest uptake was seen in women at highest risk carrying $B R C A 1 / 2$ mutations or in those with a $50 \%$ probability of having a mutation $(1 / 114,0.9 \%)$. Low uptake in $B R C A 1 / 2$ carriers has been reported previously in a Canadian (Metcalfe et al, 2007) and an international study (Metcalfe et al, 2008) and may be related to beliefs that risk reduction from tamoxifen may not be sufficient and the knowledge that BRCA1related cancers are largely oestrogen receptor negative (Table 2). In the study by Metcalfe et al (2008), no BRCA1/2 carriers from Norway, Italy, Holland or France accepted tamoxifen, whereas $12.4 \%$ of women with a known BRCA mutation from the United States of America took tamoxifen for prophylaxis. The uptake of $9 \%$ in those testing negative for a family mutation who may still be at moderate risk ( $\geqslant 17 \%$ lifetime risk by the Tyrer-Cuzick model) was similar to that for other moderate risk women in the present study (Smith et al, 2007).

Tamoxifen uptake in high-risk populations is generally regarded as low, and a lack of advocacy at the international level has seen mixed messages as to the effectiveness and appropriateness of tamoxifen for the prevention of breast cancer, which may impact on the public's perception of preventive therapy (Rahman and Pruthi, 2012). However, as shown in Table 4 uptake is highly variable and seems dependant on the clinical settings in which tamoxifen is offered, whether a consecutive or selected series was used, or whether estimates were made from whole populations (Ropka et al, 2010; Table 4). The first published tamoxifen uptake study by Port et al (2001) evaluated uptake in women identified to be at high risk in the practices of four surgeons at the Memorial Sloan Kettering Cancer Centre. Women were provided with educational sessions and literature delineating the risks and benefits of tamoxifen and offered tamoxifen immediately after

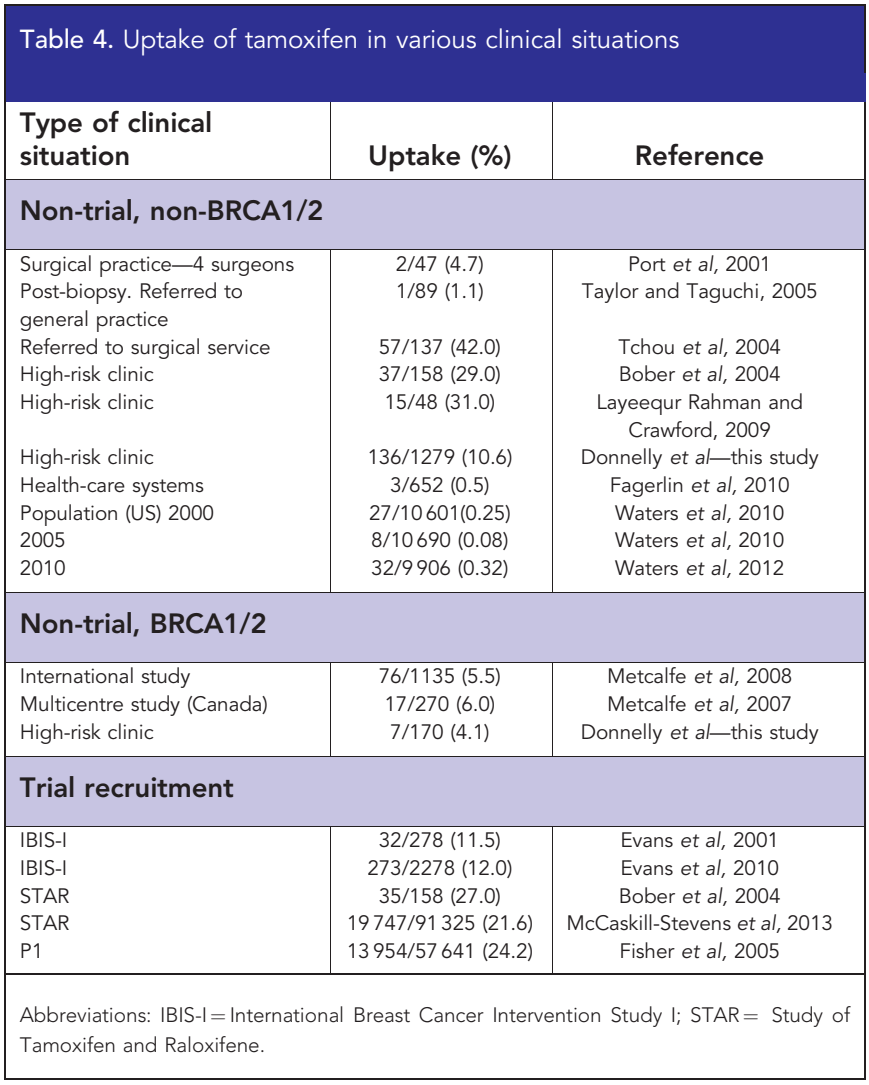

this process. Two of the forty-seven women identified (4.7\%) actually took tamoxifen. A similarly low uptake (1 of $89,1.1 \%)$ was reported from another surgical series (Taylor and Taguchi, 2005).

Tchou et al (2004) identified 219 women by retrospective chart review of those who had contacted their centre expressing an interest in the NSABP P1 study. Of these, 137 women were offered tamoxifen and $57(42.0 \%)$ decided to take it. The women were at variable risk of breast cancer by Gail score and 68 (49.6\%) had a diagnosis of LCIS or atypical hyperplasia. In the study reported by Bober et al (2004), 129 women were recruited from a high-risk programme, physician practice, or those wishing to consider entry to the STAR trial. Two months after counselling by two physicians at a Cancer Risk and Prevention Programme, 37 (28.7\%) of women wished to take tamoxifen and $35(27.1 \%)$ wished to enter the STAR trial. Evidence from Rondanina et al (2008) suggests that willingness to take tamoxifen was linked to satisfaction with study personnel, lower breast cancer worry, lower-risk perception and younger age, highlighting the value of counselling in promoting psychological well-being. However, that is not to say that opinions remain static. In the study of Goldenberg et al (2007), 99 women at high risk who had already declined to take tamoxifen underwent random peri-areolar fine needle aspiration. After the result, 51 out of 99 (51.5\%) had a normal cells detected and none of these wished to take tamoxifen. Thirty had borderline atypia and two of these chose tamoxifen, whereas 9 of the 18 with atypia chose to take tamoxifen. Overall, 11 out of 99 (11.1\%) changed their minds concerning their original decision not to take tamoxifen (Goldenberg et al, 2007).

The studies outlined above indicate the variety of approaches to detect and offer women tamoxifen from surgical practices, after referral back to family physicians, women interested in joining a prevention trial and after random peri-areolar fine needle aspiration and also from a specialist high-risk clinic. The variation in methods across studies may reflect the wide variation in uptake of tamoxifen, ranging from 1.1 to $42.0 \%$. Women in the current study were selected to be offered tamoxifen in that they had to be referred to the FHC by their family physician. Once determined to be at increased risk, all eligible women were offered the opportunity to take tamoxifen, thus minimising potential selection bias and as such our results may therefore reflect an approximation of uptake expected in this population of premenopausal women attending FHCs.

An alternative approach to identify women at high risk was taken by Fagerlin et al (2010). These investigators were allowed to access the records of women enrolled into two US health-care systems. Women judged to be at high risk, based on their records, were contacted and 632 postmenopausal women received an explanation of the pros and cons of the use of tamoxifen and raloxifene for prevention of breast cancer. None of the women started tamoxifen and two took raloxifene suggesting that this method of access to high-risk women may not be effective (Fagerlin et al, 2010).

Another approach to assess uptake has involved the biannual US National Health Information Surveys whereby the health of a population subgroup is evaluated by trained surveyors. The surveys again show that very low numbers of women are willing to take tamoxifen in the general surveyed population (Table 3).

The reasons for tamoxifen acceptance or decline were explored in the current study via semi-structured interviews with 15 women taking tamoxifen and 15 who did not. This methodology was deemed more conducive to obtaining in-depth insight into beliefs, experience, and emotion than using questionnaires. In both groups of women, the same four themes emerged: side effects, the impact of others' experience on beliefs about tamoxifen, tamoxifen as a cancer drug, and a reminder of risk. The low uptake of tamoxifen by American women has previously been explained by concerns over its side-effect profile and women's inconsistent perceptions of personal risk (Bastian et al, 2001; Meiser et al, 2003; Bober et al, 2004; Melnikow et al, 2005). All women in our study asked 
significant others who knew about or had taken tamoxifen and were influenced by their experience. This demonstrates how knowledge about tamoxifen is constructed within the family history of high-risk women, and how experiences of friends and close relatives help to formulate beliefs (Kenen et al, 2003) surrounding the efficacy and side-effect profile of tamoxifen. The social factors that contribute to women's beliefs about tamoxifen may therefore be key in explaining her decision to take or decline tamoxifen therapy. For example, women with significant family members who had a negative experience of tamoxifen cited those experiences as key in formulating their perception of tamoxifen, which in turn impacted on their likelihood to take tamoxifen for prevention. Tamoxifen was viewed by our participants as a cancer drug, which evoked painful memories for some. Despite longstanding use as a preventive agent, tamoxifen is commonly perceived as a breast cancer treatment (Donovan et al, 2003) and this was reflected in our participants' concern that daily medication would remind them of their risk. Some women confused the side effects of chemotherapy with the expected side effects of tamoxifen treatment and highlighted a need for information and support services to specifically address this and other misconceptions. Our findings echo those from an interview study with 27 women most of whom were considering tamoxifen in a primary care setting, where the issue of side effects and the association with 'chemotherapy' were identified as barriers to uptake (Heisey et al, 2006).

Previous research has indicated that the decision to engage in chemoprevention of breast cancer is a preference-sensitive decision (Mulley and Sepucha, 2002; Lippman, 2006; Ropka et al, 2010) that asks the woman to explore her own needs and values, how she perceives her own risk of developing the disease (Altschuler and Somkin, 2005), and to anticipate how the drug will impact on her both physically, emotionally, and on her life in general. Indeed, Bastian et al (2001) and Bober et al (2004) report that increased cancer risk perceptions and anxiety are integral to whether a woman will engage with chemoprevention. The offer of tamoxifen for prevention of breast cancer requires women to be able to understand and evaluate the risk associated with chemoprevention (Kaplan et al, 2012). However, Salant et al (2006) found that women understood breast cancer risk in the context of physical or embodied symptoms rather than a numerical concept (Salant et al, 2006). Rahman and Pruthi (2012) argued that uptake of chemoprevention may be greater if there were available biomarkers to give indication of the effectiveness of tamoxifen in the individual. Eligible women in our study were made aware that they would receive information on their breast density change after 1 year of taking tamoxifen, but this was not brought up by women as an incentive to take tamoxifen. The complexity in understanding breast density and the abstract nature of risk to these women may to some extent explain why uptake of chemoprevention is seemingly lower than expected among this group of women. Previous studies indicate that uptake also depends on clinician's recommendations (Cyrus-David and Strom, 2001; Malek et al, 2004; Taylor and Taguchi, 2005) and discussion of tamoxifen as a risk management option (Kaplan et al, 2006). Clinicians should be aware of how beliefs surrounding tamoxifen prevention are constructed and the impact this may have on women's willingness to engage in preventive therapy.

The strengths of the study include the focus on consecutive women, which engenders confidence in the figures for uptake in this clinical situation. All women initially deemed eligible were offered tamoxifen, but $17.2 \%$ reported ineligibility based on the protocol criteria that were not reported in available medical records. Including a qualitative study enabled in-depth exploration of the issues pertinent to how women at increased risk make decisions regarding tamoxifen prevention. Utilising a semi-structured approach to these interviews enabled women to highlight factors that were important to their decision making, something that may be lost if a larger scale, questionnaire approach had been adopted.
This study was limited by most women not having a face-to-face appointment to discuss the study invitation with a clinician. Our data have shown that uptake of tamoxifen in a consecutive series of premenopausal women was similar to that previously ascertained in a randomised controlled trial (IBIS-I). Clinicians should be aware that beliefs surrounding chemoprevention are constructed in a social and personal context and should acknowledge the impact these beliefs have on women's willingness to engage with prevention.

\section{ACKNOWLEDGEMENTS}

We thank Dr Jamie Sergeant for providing guidance on the uptake analysis. This article presents independent research funded by the National Institute for Health Research (NIHR) under its Research for Patient Benefit programme (Reference Number PB-PG-011021342). The views expressed are those of the author(s) and not necessarily those of the NHS, the NIHR, or the Department of Health. Gareth Evans is an NIHR senior investigator. Genesis Breast Cancer Prevention (Ref: GA09-001/GA10-002).

\section{CONFLICT OF INTEREST}

The authors declare no conflict of interest.

\section{REFERENCES}

Altschuler A, Somkin CP (2005) Women's decision making about whether or not to use breast cancer chemoprevention. Women Health 41: 81-95.

Bastian LA, Lipkus AM, Kuchibhata MN, Weng HH, Halabi S, Ryan PD, Skinner CS, Rimer BK (2001) Women's interest in chemoprevention for breast cancer. Arch Intern Med 161: 1639-1644.

Bober SL, Hoke LA, Duda RB, Regan MM, Tung NM (2004) Decision-making about tamoxifen in women at high risk for breast cancer: clinical and psychological factors. J Clin Oncol 22: 4951-4957.

Cheng WF, Lin HH, Torng PL, Huang SC (1997) Comparison of endometrial changes among symptomatic tamoxifen-treated and non treated premenopausal and postmenopausal breast cancer patients. Gynecol Oncol 66: $233-237$.

Cuzick J, Forbes JF, Sestak I, Cawthorn S, Hamed H, Holli K, Howell A, International Breast Cancer Intervention Study I Investigators (2007) Long-term results of tamoxifen prophylaxis for breast cancer-96-month follow-up of the randomized IBIS-I trial. J Natl Cancer Inst 99: 272-282.

Cuzick J, Sestak I, Bonanni B, Costantino JP, Cummings S, DeCensi A, Dowsett M, Forbes JF, Ford L, LaCroix AZ, Mershon J, Mitlak BH, Powles T, Veronesi U, Vogel V, Wickerham DL, SERM Chemoprevention of Breast Cancer Overview Group (2013) Selective oestrogen receptor modulators in prevention of breast cancer: an updated meta-analysis of individual participant data. Lancet 381: 1827-1834.

Cyrus-David MS, Strom SS (2001) Chemoprevention of breast cancer with selective estrogen receptor modulators: views from broadly diverse focus groups of women with elevated risk for breast cancer. Psychooncology 10: $521-533$.

Donovan R, Jalleh G, Jones S (2003) The word 'cancer': reframing the context to reduce anxiety arousal. Aust N Z J Public Health 27: 291-293.

Evans DG, Harvie M, Bundred N, Howell A (2010) Uptake of breast cancer prevention and screening trials. J Med Genet 47: 853-855.

Evans DGR, Lalloo F, Shenton A, Boggis C, Howell A (2001) Uptake of screening and prevention in women at very high risk of breast cancer. Lancet 358: 889-890.

Fagerlin A, Zikmund-Fisher BJ, Nair V, Derry HA, McClure JB, Greene S, Stark A, Hensley Alford S, Lantz P, Hayes DF, Wiese C, Claud Zweig S, Pitsch R, Jankovic A, Ubel PA (2010) Women's decisions regarding tamoxifen for breast cancer prevention: responses to a tailored decision aid. Breast Cancer Res Treat 119: 613-620.

Fisher B, Costantino JP, Wickerham DL, Cecchini RS, Cronin WM, Robidoux A, Kavanah MT, Atkins JN, Margolese RG, Runowicz CD, James JM, Ford LG, Wolmark N (2005) Tamoxifen for the prevention of breast 
cancer: current status of the National Surgical Adjuvant Breast and Bowel Project P-1 study. J Natl Cancer Inst 97: 1652-1662.

Fisher B, Costantino JP, Wickerham DL, Redmond CK, Kavanah M, Cronin WM, Vogel V, Robidoux A, Dimitrov N, Atkins J, Daly M, Wieand S, Tan-Chiu E, Ford L, Wolmark N (1998) Tamoxifen for prevention of breast cancer: report of the National Surgical Adjuvant Breast and Bowel Project P-1 Study. J Natl Cancer Inst 90: 1371-1388.

Gail MH, Costantino JP, Bryant J, Croyle R, Freedman L, Helzlsouer K, Vogel V (1999) Weighing the risks and benefits of tamoxifen treatment for preventing breast cancer. J Natl Cancer Inst 91: 1829-1846. Review. Erratum in: J Natl Cancer Inst 2000 92: 275.

Goldenberg VK, Seewaldt VL, Scott V, Bean GR, Broadwater G, Fabian C, Kimler B, Zalles C, Lipkus IM (2007) Atypia in random periareolar fine-needle aspiration affects the decision of women at high risk to take tamoxifen for breast cancer chemoprevention. Cancer Epidemiol Biomarkers Prev 16: 1032-1034.

Heisey R, Pimlott N, Clemons M, Cummings S, Drummond N (2006) Women's views on chemoprevention of breast cancer: qualitative study. Can Fam Physician 52: 624-625.

Juraskova I, Butow P, Lopez A, Seccombe M, Boyle F, McCarthy N, Forbes JF (2007) Improving informed consent to clinical trials: Successful piloting of a decision aid. J Clin Oncol 25: 1443-1444.

Kaplan C, Haas J, Perez-Stable EJ, Gregorich S, Somkin C, Des Jarlais G, Kerlikowske K (2006) Breast cancer risk reduction options: discussion, and use among women from four ethnic groups. Cancer Epidemiol Biomark Prev 15: 162-166.

Kaplan CP, Kim SE, Wong ST, Sawaya GF, Walsh JME, Perez-Stable EJ (2012) Willingness to use tamoxifen to prevent breast cancer among diverse women. Breast Cancer Res Treat 133: 357-366.

Kenen R, Ardern Jones A, Eeles R (2003) Family stories and the use of heuristics: women from suspected hereditary breast and ovarian cancer (HBOC) families. Sociol Health Illn 25: 838-865.

Layeequr Rahman R, Crawford S (2009) Chemoprevention Indication Score: a user-friendly tool for prevention of breast cancer-pilot analysis. Breast 18: $289-293$.

Lippman SM (2006) The dilemma and promise of cancer chemoprevention. Nat Clin Pract Oncol 3: 523.

Malek K, Fink AK, Thwin SS, Gurwitz J, Ganz PA, Silliman RA (2004) The relationship among physicians' specialty, perceptions of the risks and benefits of adjuvant tamoxifen therapy, and its recommendation in older patients with breast cancer. Med Care 42: 700-706.

McCaskill-Stevens W, Wilson JW, Cook ED, Edwards CL, Gibson RV, McElwain DL, Figueroa-Moseley CD, Paskett ED, Roberson NL, Wickerham DL, Wolmark N (2013) National Surgical Adjuvant Breast and Bowel Project Study of Tamoxifen and Raloxifene trial: advancing the science of recruitment and breast cancer risk assessment in minority communities. Clin Trials 10: 280-291.

McIntosh A, Shaw C, Evans G, Turnbull N, Bahar N, Barclay M, Easton D, Emery J, Gray J, Halpin J, Hopwood P, McKay J, Sheppard C, Sibbering M, Watson W, Wailoo A, Hutchinson A (2004) Clinical Guidelines and Evidence Review for the Classification and Care of Women at Risk of Familial Breast Cancer. National Collaborating Centre for Primary Care/ University of Sheffield NICE guidelineCG041: London, Updated 2006. Available at http://www.nice.org.uk.

Meiser B, Butow P, Price M, Bennett B, Berry G, Tucker K, National Consortium for Research into Familial Breast Cancer Psychological Group (2003) Attitudes to prophylactic surgery and chemoprevention in Australian women at increased risk for breast cancer. J Womens Health 12: 769-778.

Melnikow J, Paterniti D, Azari R, Kuenneth C, Birch S, Kuppermann M, Nuovo J, Keyzer J, Henderson S (2005) Preferences of women evaluating risks of tamoxifen (POWER) study of preferences for tamoxifen for breast cancer risk reduction. Cancer 103: 1996-2005.

Metcalfe KA, Birenbaum-Carmeli D, Lubinski J, Gronwald J, Lynch H, Moller P, Ghadirian P, Foulkes WD, Klijn J, Friedman E, Kim-Sing C, Ainsworth P, Rosen B, Domchek S, Wagner T, Tung N, Manoukian S, Couch F, Sun P, Narod SA. Hereditary Breast Cancer Clinical Study Group (2008) International variation in rates of uptake of preventive options in BRCA1 and BRCA2 mutation carriers. Int J Cancer 122: 2017-2022.

Metcalfe KA, Ghadirian P, Rosen B, Foulkes W, Kim-Sing C, Eisen A, Ainsworth P, Horsman D, Maugard C, Provencher D, Robideaux A, Gilchrist D, Chudley A, Lemire EG, Armel S, Finch A, Sun P, Narod SA
(2007) Variation in rates of uptake of preventive options by Canadian women carrying the BRCA1 or BRCA2 genetic mutation. Open Med 1: e92-e98.

Mulley AG, Sepucha K (2002) Making good decisions about breast cancer chemoprevention. Ann Intern Med 137: 52-54.

National Comprehensive Cancer Network (2009) NCCN clinical practice guidelines in oncology: Breast cancer risk reduction, v. 2. http:// www.nccn.org.

National Institute for Health and Care Excellence (NICE) (2013) Familial breast cancer (CG164): Classification and care of people at risk of familial breast cancer and management of breast cancer and related risks in people with a family history of breast cancer. Issued: June. http://www.nice.org.uk/ guidance/index.jsp?action=byID\&o= 14188 .

Port ER, Montgomery LL, Heerd AS, Borgen PI (2001) Patient reluctance toward tamoxifen use for breast cancer primary prevention. Ann Surg Oncol 8: 580-585.

Powles TJ, Ashley S, Tidy A, Smith IE, Dowsett M (2007) Twenty-year follow-up of the Royal Marsden randomized, double-blinded tamoxifen breast cancer prevention trial. J Natl Cancer Inst 99: 283-290.

Rahman RL, Pruthi S (2012) Chemoprevention of breast cancer: the paradox of evidence versus advocacy inaction. Cancers 4: 1146-1160.

Ritchie J, Lewis J (2003) Qualitative Research Practice: A Guide for Social Science Students and Researchers. Sage Publications: London.

Rondanina G, Putoni M, Severi G, Varricchio C, Zunino A, Feroce I, Bonanni B, Decensi A (2008) Psychological and clinical factors implicated in decision making about a trial of low-dose tamoxifen in hormone replacement therapy users. J Clin Oncol 26: 1537-1543.

Ropka ME, Keim J, Philbrick JT (2010) Patient decisions about breast cancer chemoprevention: a systematic review and meta-analysis. J Clin Oncol 28 : 3090-3095.

Salant T, Ganschow PS, Olopade OI, Lauderdale DS (2006) Why take it if you don't have anything? Breast cancer risk perceptions and preventive choices at a public hospital. J Gen Intern Med 21: 779-785.

Smith A, Moran A, Boyd MC, Bulman M, Shenton A, Smith L, Iddenden R, Woodward ER, Lalloo F, Maher ER, Evans DGR (2007) The trouble with phenocopies: are those testing negative for a family BRCA1/2 mutation really at population risk? J Med Genet 44: 10-15.

Taylor R, Taguchi K (2005) Tamoxifen for breast cancer chemoprevention: low uptake by high-risk women after evaluation of a breast lump. Ann Fam Med 3: 242-247.

Tchou J, Hou N, Rademaker A, Jordan VC, Morrow M (2004) Acceptance of tamoxifen chemoprevention by physicians and women at risk. Cancer 100: $1800-1806$.

Tyrer J, Duffy SW, Cuzick J (2004) A breast cancer prediction model incorporating familial and personal risk factors. Stat Med 23: 1111-1130.

US Food and Drug Administration (1998) http://www.fda.gov/NewsEvents/ Testimony/ucm115118.htm.

Veronesi U, Maisonneuve P, Rotmensz N, Bonanni B, Boyle P, Viale G, Costa A, Sacchini V, Travaglini R, D'Aiuto G, Oliviero P, Lovison F, Gucciardo G, del Turco MR, Muraca MG, Pizzichetta MA, Conforti S, Decensi A, Italian Tamoxifen Study Group (2007) Tamoxifen for the prevention of breast cancer: late results of the Italian Randomized Tamoxifen Prevention Trial among women with hysterectomy. J Natl Cancer Inst 99: 727-737.

Visvanathan K, Hurley P, Bantug E, Brown P, Col NF, Cuzick J, Davidson NE, Decensi A, Fabian C, Ford L, Garber J, Katapodi M, Kramer B, Morrow M, Parker B, Runowicz C, Vogel VG, Wade JL, Lippman SM (2013) Use of pharmacologic interventions for breast cancer risk reduction: American Society of Clinical Oncology Clinical Practice Guideline. J Clin Oncol 31: 2942-2962.

Waters EA, Cronin KA, Graubard BI, Han PK, Feedman AN (2010) Prevalence of tamoxifen use for breast cancer chemoprevention among US women. Cancer Epidemiol Biomarkers Prev 19: 443-446.

Waters EA, McNeel TS, McCaskill Stevens W, Freedman AN (2012) Use of tamoxifen and raloxifene for breast cancer chemoprevention in 2010. Breast Cancer Res Treat 134: 875-880.

This work is published under the standard license to publish agreement. After 12 months the work will become freely available and the license terms will switch to a Creative Commons AttributionNonCommercial-Share Alike 3.0 Unported License. 